\title{
El protomedicato en el desarrollo de la salubridad en Chile durante la Colonia y la República
}

\author{
ENRIQUE LAVAL R.
}

\section{Protomedicate in the public health development in Chile during the Colony and the Republic}

El cuadro de las actividades sanitarias y asistenciales en el Nuevo Mundo, en la época de la Conquista y de la Colonia no se diferenció mayormente en los distintos países americanos, ya que España trasplantó a ellos las instituciones, usos y costumbres de la metrópoli. Así por ejemplo, los Concejos del Reino de Castilla que funcionaron con el nombre de Cabildos y cuyas atribuciones tan amplias, sin delimitación precisa, les permitió intervenir en toda la vida social, política y económica de la Colonia, quedando centradas en ellos la funciones legislativas, judiciales y ejecutivas. De aquí que las primeras medidas sanitarias implantadas en el país fueron adoptadas por el Cabildo, tomando a su cargo la salubridad urbana, el control de los alimentos y bebidas, el aprovisionamiento de agua potable, las medidas preventivas y curativas en épocas de epidemias, el control de los hospitales y del ejercicio de las profesiones médicas, la designación de administradores y demás personal de los nosocomios.

Las atribuciones de dichos Cabildos, fueron limitándose poco a poco, con la implantación de otras instituciones españolas y la dictación de leyes, ordenanzas y reales cédulas que reglamentaron todos los aspectos de la vida del país. Entre las nuevas instituciones emergió el Protomedicato ${ }^{1,2,3}$.

El protomedicato había nacido en España en el siglo XV como tribunal encargado de autorizar, controlar y aplicar medidas punitivas en el ejercicio de las profesiones médicas y de organismo asesor del Gobierno en todo lo concerniente a salubridad. Incorporado a los países americanos con similar carácter, sobrevivió, en la inmensa mayoría de ellos, hasta la era republicana y paulatinamente fueron disminuyéndole atribuciones hasta su extinción total. ${ }^{12}$

En 1691, el Protomedicato de Lima designó como su delegado en Chile al doctor don José Dávalos Peralta, pero el establecimiento de la Universidad de San Felipe, con su cátedra de Prima de Medicina, hizo recaer legalmente en 1756, la designación de Protomédico en su profesor el doctor Domingo Nevin y en sus sucesores ${ }^{3}$.

Pero, todas las medidas adoptadas por el Cabildo o por el Protomedicato no fueron capaces de influir en la obtención de un estado sanitario medianamente satisfactorio, ya que el país vivía permanente diezmado por la viruela y el tifus exantemático ${ }^{1}$.

De todo este período que abarca más de dos siglos de la Colonia, sólo merece recordarse la audacia, inteligencia y decisión de un fraile de la orden de San Juan de Dios, fray Pedro Manuel Chaparro, que fue el primero en América del Sur en practicar la variolización, que comenzó en 1765 y posteriormen- te, el primero en utilizar la vacuna en Chile en $1805 .{ }^{4}$ Poco a poco se fueron segregando atribuciones al Protomedicato. En octubre de 1808, el gobierno creó la Junta Central de Vacuna destinada a propagarla, como consecuencia de la llegada al país del doctor Julián Grajales, que formaba parte de la expedición enviada por España a América a cargo del doctor Balmis para difundir la vacuna. Esta junta con algunas alternativas estuvo en funciones hasta la dictación de nuestro primer Código Sanitario en $1918.1,5$

El 19 de noviembre de 1842, se creó la Universidad de Chile y la ley que le dio lugar, encargo a la Facultad de Medicina "velar por el cultivo y adelantamiento de las ciencias médicas, dedicarse especialmente al estudio de las enfermedades endémicas en Chile y de las epidémicas que afligen más frecuentemente la población de las ciudades y campos del territorio chileno, dando a conocer los mejores medios preservativos y curativos, dirigiendo sus observaciones a las mejora de la higiene pública y doméstica", atribuciones todas que pertenecían al Protomedicato.

La dictación de nuevas leyes circunscribieron en definitiva esta institución varias veces secular, a una mera comisión consultativa del gobierno en materia de salubridad, perdiendo definitivamente su carácter de tribunal y el cargo de Protomédico vino a confundirse con el de Decano de la Facultad de Medicina de la Universidad de Chile. ${ }^{1,2}$

El Tribunal del Protomedicato existió en Chile con sus atribuciones docentes, inspectivas y judiciales hasta 1875 .

Permaneció únicamente como institución de supervigilancia de policía médico-sanitaria hasta 1892, desapareciendo con motivo de la dictación de la ley que creó el Consejo Superior de Higiene Pública e Instituto de Higiene, el 16 de septiembre de aquel año. ${ }^{6}$

\section{Bibliografía}

1.- Laval M E, García V R. Síntesis del desarrollo histórico de la salubridad en Chile. Revista del Servicio Nacional de Salud 1956; 1: 23.

2.- Benavente G R. El Protomedicato en Chile. Santiago de Chile. Soc. Impta. Y Lit Universo 1928.

3.- Ferrer P L. Historia General de la Medicina en Chile. Tomo I Talca, Chile. Impta. Talca 1904.

4.- Laval R E. Notas históricas sobre la viruela en Chile. Rev Chil Infect 1985; 2: 138.

5.- Laval R E. La expedición de Balmis. Rev Chil Infect.1990; 7: 45.

6.- Poirier E. Chile en 1908. Santiago de Chile. Impta Lit y Encuad. Barcelona 1909. 